\title{
PREDICTIVE MODEL AND OPTIMIZATION OF PROCESSING PARAMETERS FOR PLASTIC INJECTION MOULDING
}

\author{
MODEL ZA NAPOVEDOVANJE IN OPTIMIZACIJO PROCESNIH \\ PARAMETROV PRI BRIZGANJU PLASTIKE
}

\author{
Davorin Kramar'1, Djordje Cica ${ }^{2}$ \\ ${ }^{1}$ University of Ljubljana, Faculty of Mechanical Engineering, Ljubljana, Slovenia \\ ${ }^{2}$ University of Banja Luka, Faculty of Mechanical Engineering, Banja Luka, Bosnia and Herzegovina \\ davorin.kramar@fs.uni-lj.si \\ Prejem rokopisa - received: 2016-06-25; sprejem za objavo - accepted for publication: 2017-01-16
}

doi:10.17222/mit.2016.129

\begin{abstract}
Injection molding is one of the most widely used processes for producing engineered parts in the plastics industry. The objective of this study is to propose a fuzzy expert system for the prediction of mechanical properties of injection-molded parts where the fuzzy system is optimized using particle-swarm optimization. The input process parameters were the mold temperature, melt temperature, injection velocity, packing pressure, cooling time and packing time. The predicted values were in good agreement with the experimental ones, which indicates that the developed particle-swarm-optimization-based fuzzy expert system can be effectively used to predict the mechanical properties of molded parts. In addition, optimization based on a particle-swarmoptimization algorithm was carried out to obtain the optimum process parameters based on the objective to maximize the tensile strength of the molded product.

Keywords: plastics, injection molding, particle-swarm optimization, tensile strength
\end{abstract}

Brizganje je eden izmed najpogosteje uporabljenih postopkov za izdelavo inženirskih delov v industriji plastike. Cilj te raziskave je predlagati enostavni ekspertni sistem za napovedovanje mehanskih lastnosti delov brizganih kosov, kjer je enostavni sistem optimiziran z uporabo optimizacije z rojem delcev. Vhodni parametri procesa so temperature orodja, temperatura taline, hitrost brizganja, zapiralni pritisk, čas hlajenja in zapiralni čas. Napovedane vrednosti se dobro ujemajo z eksperimentalnimi, kar kaže, da se razvit enostavni ekspertni sistem na osnovi optimizacije z rojem delcev lahko učinkovito uporablja za napovedovanje mehanskih lastnosti brizganih delov. Algoritem optimizacije z rojem delcev je podal tudi optimalne procesne parametre za doseganje čim višje natezne trdnosti brizganega izdelka.

Ključne besede: plastika, injekcijsko brizganje, optimizacija z roji delcev, natezna trdnost

\section{INTRODUCTION}

Plastic injection molding is the most widely used manufacturing process for the high-volume production of relatively complex thermoplastic parts by injecting a material into a mold. Within this process, a high-pressure fluid polymer is injected to the cavity with a desired form. In the next step, under high pressure, while cooling, the fluid solidifies. However, plastic injection molding is a very complex manufacturing process due to the strong nonlinearities and a large number of interrelated parameters. Over the last few decades, artificial-intelligence (AI) methods have become the preferred trend, applied by most researchers for the optimization and prediction of various parameters of the injection-molding process.

S. Kenig et al. ${ }^{1}$ used a feed-forward artificial neural network (ANN) with an error back-propagation algorithm for the adequate control of product properties in injection-molded plastics. W. C. Chen et al. ${ }^{2}$ developed a self-organizing map and a back-propagation neural-network model to generate a dynamic quality predictor for the plastic-injection-molding process. C. Ozek and Y. H. Celik $^{3}$ developed software to predict the quality of the injected parts through an ANN model. H. M. Sadeghi ${ }^{4}$ studied the possibility of predicting the quality or soundness of the injected parts through an ANN model and based on computer-aided engineering software simulations. C. F. Juang et al. ${ }^{5}$ developed a Takagi-SugenoKang-type recurrent fuzzy neural networks for the control of the mold temperature. C. Karatas et al. ${ }^{6}$ developed an ANN model to determine the yield length in the plastic molding of commercial plastics. M. Altan ${ }^{7}$ studied the optimum injection-molding conditions for the minimum shrinkage based on Taguchi methods, ANOVA and ANN. H. Shi et al. ${ }^{8}$ proposed an adaptive optimization method based on an ANN model for the minimization of the warpage of injection-molded parts. A. Krimpenis et al. ${ }^{9}$ proposed ANN meta-models in order to generalize from the examples connecting input-process variables to output variables. A neural model is employed in the fitness function of the genetic algorithm (GA) for optimization of the injection-molding process. C. Shen et al. ${ }^{10}$ proposed a method based on a combination of the ANN and GA for optimization of the injection-molding process in order to improve the quality index of the volumetric-shrinkage variation in the part. 
B. Ozcelik and T. Erzurumlu ${ }^{11}$ determined the most important process parameters influencing warpage using finite-element-analysis results based on ANOVA, while an ANN was interfaced with an effective GA to find the minimum warpage value. Chen et al. ${ }^{12}$ presented an effective approach in a soft-computing paradigm for the process-parameter optimization of the plastic-injectionmolding process. The proposed approach integrates Taguchi's parameter-design method, ANN, GA and engineering-optimization concepts. Li et al. ${ }^{13}$ presented a genetic neural fuzzy system to construct a quality-prediction model for the injection process from the input and output data. Mathivanan and Parthasarathy ${ }^{14}$ investigate sink depths in injection-molded thermoplastic components by integrating the finite-element-flow analysis with the central composite design of experiments and GA. Deng et al. ${ }^{15}$ proposed a hybrid of the mode-pursuing sampling method and the GA for the minimization of injection-molding warpage. Park and Nguyen ${ }^{16}$ presented an injection-molding-process optimization of a plastic car fender related to the energy consumption and product quality. J. Cheng et al. ${ }^{17}$ proposed a multiobjective optimization model including both mold and process parameters as design variables in order to achieve the optimum parameter schemes in accordance with practical requirements of injection molding. J. Cheng et al. ${ }^{18}$ developed a fuzzy moldability-evaluation approach for the optimization of injection-mold schemes based on the variable weight-profit vector. K. T. Chiang and F. P. Chang ${ }^{19}$ and K. T. Chiang ${ }^{20}$ proposed an approach for optimizing process parameters of an injection-molded part with a thin shell feature based on the orthogonal array with the grey relational analysis and fuzzy logical analysis.

Despite the fact that there are numerous applications of the AI in modeling the injection-molding process reported in the literature, a review of the literature shows that only few research works are based on the fuzzy theory. Furthermore, previous approaches were based on the usual approach to designing a fuzzy system by encoding expert knowledge in a direct way using rules with linguistic labels. However, knowledge acquisition is not a trivial task so, in the present paper, an attempt was made to design an optimized fuzzy expert system (FES)

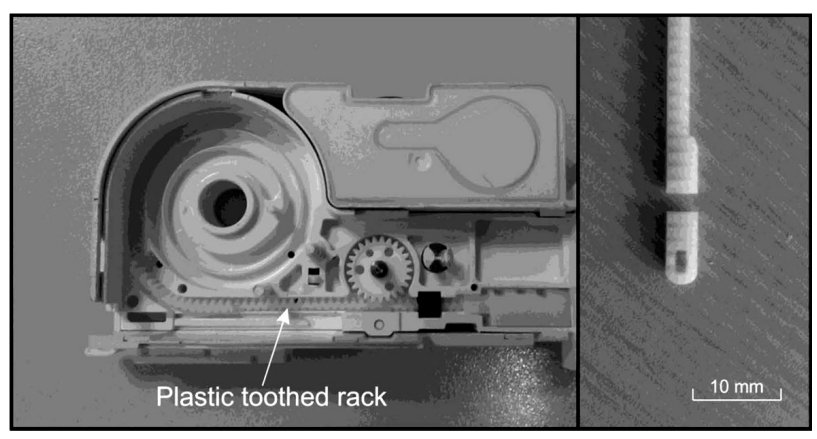

Figure 1: Plastic-toothed rack within a driving gear (left) and the usual cause of breakage (right) using a particle-swarm-optimization algorithm for predicting the mechanical properties of the molded parts. Furthermore, the particle-swarm-optimization (PSO) algorithm is used in the process optimization in order to improve the mechanical properties of the injectionmolded parts.

\section{EXPERIMENTAL PART}

According to the experience with polyoxymethilene (POM) materials, the following control factors, i.e., injection-molding-process parameters influencing product mechanical properties, were selected: the mold temperature $\left(T_{M}\right)$, the melting temperature $\left(T_{m}\right)$, the injection velocity $\left(v_{i}\right)$, the packing pressure $\left(p_{h}\right)$, the packing time $\left(t_{h}\right)$, and the cooling time $\left(t_{c}\right)$. The levels of process parameters are shown in Table 1, being selected according to material-producer specifications. All the experiments were carried out on an Engel Victory 200/50 injection-molding machine with a clamping force of 500 $\mathrm{kN}$ and a cylinder diameter of $18 \mathrm{~mm}$. The main characteristic of the investigated POM material is a high melt-flow rate of $52 \mathrm{~g} / 10 \mathrm{~min}$.

Table 1: Design of experiments and comparison between experimental results and the predicted breaking force of the injection-molded toothed rack

\begin{tabular}{|c|c|c|c|c|c|c|c|c|c|c|}
\hline \multicolumn{9}{|c|}{ Process parameters } & $\begin{array}{c}\text { Expe- } \\
\text { riment }\end{array}$ & \multicolumn{2}{|c|}{ FES } & \multicolumn{2}{|c|}{ PSOFES } \\
\hline $\begin{array}{c}T_{M} \\
\left({ }^{\circ} \mathrm{C}\right)\end{array}$ & $\begin{array}{c}T_{m} \\
\left({ }^{\circ} \mathrm{C}\right)\end{array}$ & $\begin{array}{c}V_{i} \\
(\mathrm{~mm} / \mathrm{s})\end{array}$ & $\begin{array}{c}p_{h} \\
(\mathrm{bar})\end{array}$ & $\begin{array}{c}t_{c} \\
(\mathrm{~s})\end{array}$ & $\begin{array}{c}t_{h} \\
(\mathrm{~s})\end{array}$ & $\begin{array}{c}F \\
(\mathrm{~N})\end{array}$ & $\begin{array}{c}F \\
(\mathrm{~N})\end{array}$ & $\begin{array}{c}\text { Error } \\
(\%)\end{array}$ & $\begin{array}{c}F \\
(\mathrm{~N})\end{array}$ & $\begin{array}{c}\text { Error } \\
(\%)\end{array}$ \\
\hline 70 & 185 & 20 & 1000 & 6 & 2 & 64.6 & 62.3 & 3.6 & 64.6 & 0 \\
\hline 70 & 195 & 40 & 1150 & 8 & 4 & 69.1 & 67.5 & 2.3 & 66.9 & 3.2 \\
\hline 70 & 205 & 60 & 1300 & 10 & 6 & 72.7 & 72.8 & 0.1 & 72.9 & 0.3 \\
\hline 85 & 185 & 20 & 1150 & 8 & 6 & 64.9 & 67.5 & 4 & 66.7 & 2.8 \\
\hline 85 & 195 & 40 & 1300 & 10 & 2 & 71.8 & 72.8 & 1.4 & 71.9 & 0.1 \\
\hline 85 & 205 & 60 & 1000 & 6 & 4 & 71.9 & 72.8 & 1.3 & 71.8 & 0.1 \\
\hline 100 & 185 & 40 & 1000 & 10 & 4 & 59.6 & 62.3 & 4.5 & 60.5 & 1.5 \\
\hline 100 & 195 & 60 & 1150 & 6 & 6 & 62.1 & 62.3 & 0.3 & 60.7 & 2.3 \\
\hline 100 & 205 & 20 & 1300 & 8 & 2 & 77.3 & 76.3 & 1.3 & 77.1 & 0.3 \\
\hline 70 & 185 & 60 & 1300 & 8 & 4 & 60.7 & 62.3 & 2.6 & 60.7 & 0 \\
\hline 70 & 195 & 20 & 1000 & 10 & 6 & 66.9 & 67.5 & 0.9 & 66.9 & 0 \\
\hline 70 & 205 & 40 & 1150 & 6 & 2 & 70.5 & 72.8 & 3.3 & 70.7 & 0.3 \\
\hline 85 & 185 & 40 & 1300 & 6 & 6 & 59.8 & 62.3 & 4.2 & 60.7 & 1.5 \\
\hline 85 & 195 & 60 & 1000 & 8 & 2 & 62.2 & 62.3 & 0.2 & 62.2 & 0 \\
\hline 85 & 205 & 20 & 1150 & 10 & 4 & 70.2 & 72.8 & 3.7 & 69.6 & 0.9 \\
\hline 100 & 185 & 60 & 1150 & 10 & 2 & 57.7 & 58.9 & 2.1 & 57.8 & 0.2 \\
\hline 100 & 195 & 20 & 1300 & 6 & 4 & 74.2 & 72.8 & 1.9 & 73.8 & 0.5 \\
\hline 100 & 205 & 40 & 1000 & 8 & 6 & 73.7 & 72.8 & 1.2 & 73.7 & 0 \\
\hline
\end{tabular}

In this study, POM thermoplastic with commercial designation Kepital F40-03 was utilized. The material is characterized by high strength, hardness and rigidity, thermal stability and, especially, a high melt-flow rate. As such, this material can be used as an extremely easyflowing grade for the injection molding of thin-walled precision parts. The precision of a part and mechanical properties of a product are even more important when parts for medical devices are produced. In this paper, the 
injection-molding process of a plastic toothed rack used as the driving gear of a breast-biopsy system is investigated. Beside high tolerances, dimensional stability and low friction needed for a sufficient operation, the plastic rack should fulfil high stiffness and tensile-strength requirements. The rack should not break when biopsy is executed (Figure 1).

Orthogonal array L18 was applied to run the experiments (Table 1). All the experiments were repeated 10 times, and molded samples were collected. The samples were then carefully cut to remove sprue and runner from the final product: a toothed rack. The breaking point of each rack was measured with a specially designed tension test. The average value of the breaking force for 10 rack samples was then calculated. The results of experiments are shown in Table 1.

\section{PSO-BASED FUZZY EXPERT SYSTEM}

Fuzzy logic is one of the most successful technologies for developing rule-based expert systems. According to the inventor of fuzzy logic L. A. Zadeh ${ }^{21}$, fuzzy logic attempts to formalize two human abilities: to reason in the presence of imperfect information and to carry out different mental and physical tasks without any numerical measurements or computations. A fuzzy inference system (FIS) combines the fuzzy set theory, fuzzy rules and fuzzy reasoning. According to ${ }^{22}$, a FIS is composed of three parts: a rule base, which contains the collection of fuzzy rules, a database (or dictionary) which specifies the membership functions (MFs) used in the fuzzy rules, and a reasoning mechanism, which infers the output based on the rule base, database and the given input.

In this study, the authors designed the rule base and database of the FES, based on their knowledge of the injection-molding process. In this FES, the input variables are: the mold temperature, the melt temperature, the injection velocity, the packing pressure, the cooling time and the packing time, while the output variable is the breaking force. The input variables have three MFs labeled as low, medium and high, while the output variable, that is, the breaking force, has five MFs labeled as very fine, fine, medium, coarse and very coarse. In order to describe the fuzzy sets for the input and output variables, a triangular shape of the MFs is employed. In this study, a Mamdani-type fuzzy inference system is used, due to its relatively simple structure and intuitive nature of the rule base, for correlating the injectionmolding parameters with the breaking force. However, this usual approach for the FES design is characterized by disadvantages such as dependence of the system performance on the knowledge of the human expert, adequate fuzzy rules, MFs and their boundaries. In order to overcome these shortcomings, a significant amount of research was carried out on automatic tuning of a FES using bio-inspired algorithms, such as PSO.
Particle-swarm optimization was first introduced by J. Kennedy and R. Eberhart ${ }^{23}$ who defined a swarm as a population of interactive elements or agents, able to optimize some global objective through a collaborative search in space. PSO is a population-based method where the population is referred to as a swarm. The swarm consists of a number of individuals called the particles, which are initialized with random solutions. These particles fly in a $d$-dimensional space through many iterations to search a better solution for the problem. Every particle in the swarm is represented by a specific position, initialized by the initial position and by velocity, where each particle moves in the space according to a specific velocity. Furthermore, each particle holds the information about the best position, the one associated with the best fitness value the particle has achieved so far, and the global best position, the one associated with the best fitness value found among all of the particles. In this way, the trajectory of each particle is influenced by the trajectories of the neighborhood particles as well as the flight experience of the particle itself. During the iteration time, each particle updates this information and adjusts its own trajectory in order to move towards its best position and global best position.

The PSO method has many advantages, such are its effectiveness, robustness, simplicity and extreme ease of implementation without the need for cumbersome derivative calculations. The focus of this study is to employ a PSO for optimizing an already existing fuzzy-rule-based system. The main idea is the adaptation of the parameters of the input and output MFs by the PSO according to a fitness function that specifies the design criteria in a quantitative manner. In this paper, the triangular shape of MFs is employed to describe the fuzzy sets for the input and output variables, so the optimization of MF distributions is reduced to the changes of the base widths. Furthermore, fuzzy rule weights are also optimized by the PSO.

A parametric study was carried out to find the optimum values of PSO parameters in order to achieve a good result. The fitness value of a PSO solution is estimated based on the mean absolute percentage error of each training-data sample. The error of each set of the training data is the deviation of the result (the breaking force) of the PSO-based FES from that of the desired one. The optimum values of the PSO parameters for cognitive acceleration, social acceleration, number of generations and population size were $0.3,1.3,880$ and 370, respectively. Figure 2 shows the optimized MF distributions of the input-output MFs obtained after fine-tuning using the PSO.

To verify the performances of the proposed FES, the results of these systems were compared with that obtained using the experimental tests as shown in Table 1. For the author-defined Mamdani FES, Pearson's linearcorrelation coefficient was 0.9644 , and the mean absolute percentage error was $2.2 \%$, while the maximum 
D. KRAMAR, D. CICA: PREDICTIVE MODEL AND OPTIMIZATION OF PROCESSING PARAMETERS ...
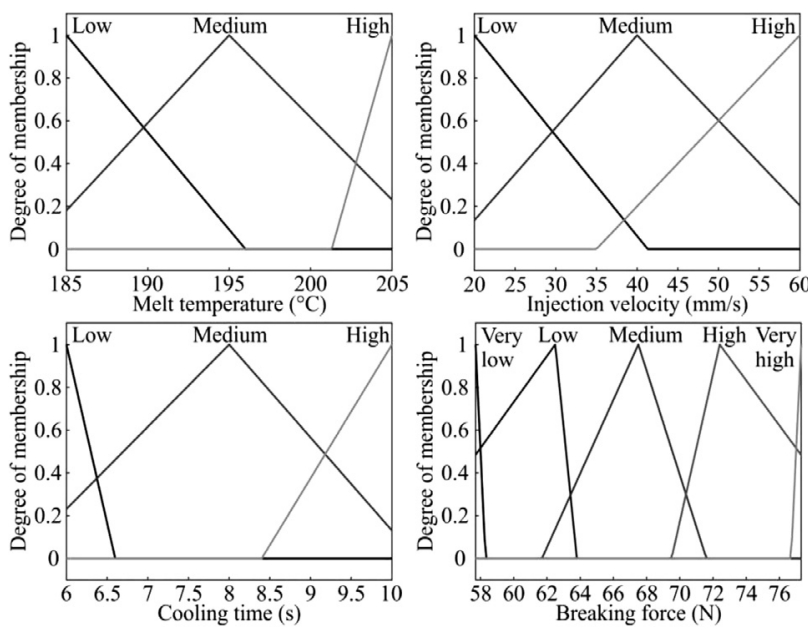

Figure 2: Optimized membership-function distributions for melt temperature, injection velocity, cooling time and breaking force of the PSO fuzzy expert system

absolute percentage error was $4.2 \%$. Pearson's linearcorrelation coefficient of the PSO-based FES was 0.9899. The mean absolute percentage error and the maximum absolute percentage error of the PSO-based FES were $0.8 \%$ and $3.2 \%$, respectively. Figure 3 shows a comparison of the predictions of the breaking force of the injection-molded toothed rack obtained using the fuzzy-rule-based expert system and the PSO-based fuzzy expert systems in terms of \% error. It is obvious that there is a very good agreement between the estimated and experimental values of the breaking force for both models. On this basis, it can be concluded that the fuzzy-logic technique is a good alternative for predicting the breaking force of the injection-molded part within the range of the input parameters under consideration. However, in almost all the cases, the prediction results using a fuzzy system optimized with a PSO algorithm are more accurate than the conventional fuzzy-rule-based expert system.

\section{INJECTION-PROCESS-PARAMETER OPTIMIZATION USING A PSO ALGORITHM}

In addition to modeling, optimization of process parameters is one of the most important elements of injection molding. The selection of optimum process parameters enables the control of the manufacturing process to achieve better quality products at a low cost and high productivity levels. Therefore, the second goal of our research was to determine the process conditions to improve the mechanical performance of the part using the PSO technique as the optimization tool.

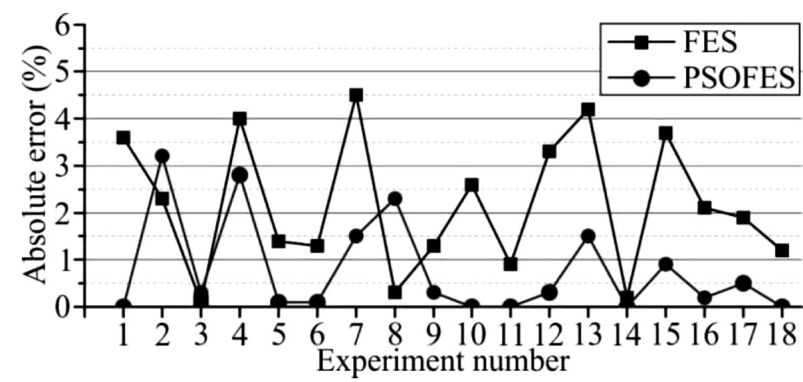

Figure 3: Error profile of the predicted breaking-force values obtained using the author-defined FES and PSO-based FES

Prior to the optimization process, it is necessary to establish the relationships between the process parameters and objective functions. For this purpose, in this paper, a systematic methodology based on the responsesurface methodology was applied. A response-surface model correlating the breaking force and the considered injection-molding parameters was developed using an ANOVA $^{24}$ of the experimental results in the form of a reduced quadratic model. The determination of the significant model degree and parameter effects was based on the $F$ and $P$ values (Table 2). Model $F$-value is a test for comparing the model variance with the residual (error) variance. If the variances are close to the same, the ratio will be close to one and it is less likely that any of the factors have a significant effect on the response. Model $F$-value is calculated using the model mean square divided by the residual mean square.

The model $F$-value of 15.88 implies the model is significant. There is only a $0.02 \%$ chance that a "model $F$-value" this large could occur due to noise. $P$-values smaller than 0.05 indicate model terms that are significant. In our case, parameters $T_{m}$ and $v_{i}$, and products $T_{M} \cdot v_{i}$, and $p_{h} \cdot t_{c}$ are significant model terms. However, for statistical reasons, models contain subsets of all the possible effects that preserve the hierarchy. A model is hierarchal if the presence of quadratic terms and interactions requires the inclusion of all the linear terms contained within those of the higher order, even if they do not appear to be significant on their own. The signal-to-noise ratio of 14.28 and $R$-squared coefficient of 0.93 indicate that the model can be used for the breaking-force prediction. The following mathematical relationship is obtained with Equation (1):

$$
\begin{aligned}
& F=-759.2212+0.40865 \cdot T_{\mathrm{M}}+8.5927 \cdot T_{\mathrm{m}}+ \\
& +0.61292 \cdot v_{i}-0.0694246 \cdot p_{\mathrm{h}}-10.2512 \cdot t_{\mathrm{c}}- \\
& -0.00910714 \cdot T_{\mathrm{M}} v_{i}+0.00876190 \cdot p_{\mathrm{h}} t_{\mathrm{c}}- \\
& -0.0209018 \cdot T_{\mathrm{m}}^{2}
\end{aligned}
$$

\begin{tabular}{|c|c|c|c|c|c|c|c|c|c|}
\hline Source & Model & $T_{\mathrm{M}}$ & $T_{\mathrm{m}}$ & $v_{i}$ & $p_{\mathrm{h}}$ & $t_{\mathrm{c}}$ & $T_{\mathrm{M}} \cdot v_{i}$ & $p_{\mathrm{h}} \cdot t_{\mathrm{c}}$ & $T_{\mathrm{m}}{ }^{2}$ \\
\hline$F$-value & 15.88 & 1.06 & 37.60 & 24.81 & 0.015 & 0.33 & 6.48 & 8.25 & 3.49 \\
\hline$P$-value & 0.0002 & 0.3307 & 0.0002 & 0.0008 & 0.9038 & 0.5774 & 0.0314 & 0.0184 & 0.0944 \\
\hline
\end{tabular}

Table 2: ANOVA of the experimental results from Table 1 
The mechanical properties of injection-molded parts are influenced by many process variables, and five key-process parameters were selected as the design variables of the mathematical model: the mold temperature, melt temperature, injection velocity, packing pressure and cooling time. The mathematical model of the injection-molding optimization problem can be formulated as follows:

Find $X=\left[T_{\mathrm{M}}, T_{\mathrm{m}}, v_{i}, p_{\mathrm{h}}, t_{\mathrm{c}}\right]$

Maximize $F(X)$

Subject to: $70=T_{\mathrm{M}}=100,185=T_{\mathrm{m}}=205,20=v_{i}=60$, $1000=p_{\mathrm{h}}=1300,6=t_{\mathrm{c}}=10$.

The optimum values of the injection-molding-process parameters were efficiently obtained with the PSO algorithm. In the PSO optimization process, the commonly used PSO operation parameters were adopted; namely, the population size, the generation size, the cognitive acceleration and the social attraction were set as 340, 1240, 0.5 and 1.25, respectively. The optimized results are listed in Table 3. Compared with the recommended process parameters, the optimized process parameters have higher values of the breaking force. The increasing percentage is approximately $19 \%$ of the average value of the breaking force $(67.2 \mathrm{~N})$.

Table 3: Optimized parameters of the injection-molding process

\begin{tabular}{|c|c|c|c|c|c|}
\hline \multicolumn{5}{|c|}{ Optimized parameters } & $\begin{array}{c}\text { Predicted } \\
\text { value }\end{array}$ \\
\hline$T_{M}$ & $T_{m}$ & $\begin{array}{c}v_{i} \\
(\mathrm{~mm} / \mathrm{s})\end{array}$ & $\begin{array}{c}p_{h} \\
(\mathrm{bar})\end{array}$ & $\begin{array}{c}t_{c} \\
(\mathrm{~s})\end{array}$ & $\begin{array}{c}F \\
(\mathrm{~N})\end{array}$ \\
\hline$\left({ }^{\circ} \mathrm{C}\right)$ & $\left({ }^{\circ} \mathrm{C}\right)$ & 20 & 1000 & 6 & 80.4 \\
\hline 100 & 205 & 20 & \\
\hline
\end{tabular}

\subsection{Verification of the optimization results}

A confirmation test is needed to verify the results of optimization. A set of 10 experimental repetitions with the optimum process-parameter settings were conducted. The results are shown in Table 4. The mean value of 10 repetitions is approximately $80 \mathrm{~N}$, which is in good agreement with the predicted value.

Table 4: Results of the confirmation test

\begin{tabular}{|c|c|c|c|c|c|c|c|c|c|c|c|}
\hline Repetition & 1 & 2 & 3 & 4 & 5 & 6 & 7 & 8 & 9 & 10 & Mean \\
\hline $\begin{array}{c}\text { Breaking } \\
\text { force (N) }\end{array}$ & 79 & 78 & 79 & 79 & 84 & 81 & 79 & 79 & 81 & 79 & 79.8 \\
\hline
\end{tabular}

\section{CONCLUSIONS}

The present work aims at estimating the mechanical properties of injection-molded parts using two fuzzy expert systems as the tools for the prediction. First, the authors designed a conventional fuzzy expert system, based on their knowledge of the injection-molding process and the predicted results for the breaking forces achieved via this system were compared to the experimental values. The results obtained indicated that the proposed fuzzy expert system has a prediction accuracy of $97.8 \%$. However, the performances of the authordefined fuzzy expert system are highly dependent on the expert knowledge, adequate fuzzy rules, membership functions and their boundaries. In order to overcome these problems and significantly improve the performance of the fuzzy expert system, a particle-swarmoptimization algorithm was interfaced with the fuzzy system. The results of the developed particle-swarmoptimization-based fuzzy expert system were compared, in terms of accuracy prediction, with the real experimental data and it was shown that the hybridization between fuzzy systems and particle-swarm optimization provides a more accurate result compared to an authordefined fuzzy expert system. The accuracy of $99.2 \%$ indicates that the particle-swarm-optimization-based fuzzy expert system can be used effectively to predict the mechanical properties for an injection-molding process.

The second objective of this work was to find the optimum process parameters to improve the mechanical properties of injection-molded parts using a particleswarm-optimization algorithm as the optimization technique. In the first stage, the response-surface methodology was deployed to establish the relationship between the process parameters and the performance of the objective functions. In the second stage, the particle-swarm-optimization algorithm was interfaced with this nonlinear model of the injection-molding system to find the optimum values of the process parameters. The same design variables as for the fuzzy expert system were considered, while the optimum values of these process parameters were obtained for the maximization of the breaking force subject to some constraints. The research results indicate that the proposed optimization method can effectively help manufacturers to determine the optimum injection-molding-process parameters and, thereby, significantly improve the mechanical performance of injection-molded parts.

\section{REFERENCES}

${ }^{1}$ S. Kenig, A. Ben-David, M. Omer, A. Sadeh, Control of properties in injection molding by neural network, Eng. Appl. Artif. Intel., 14 (2001) 6, 819-823, doi:10.1016/S0952-1976(02)00006-4

${ }^{2}$ W. C. Chen, P. H. Tai, M. W. Wang, W. J. Deng, C. T. Chen, A neural network-based approach for dynamic quality prediction in a plastic injection molding process, Expert. Syst. Appl., 35 (2008) 3, 843-849, doi:10.1016/j.eswa.2007.07.037

${ }^{3}$ C. Ozek, Y. H. Celik, Calculating Molding Parameters in Plastic Injection Molds with ANN and Developing Software, Mater. Manuf. Process, 27 (2012) 2, 160-168, doi:10.1080/10426914.2011.560224

${ }^{4}$ B. H. M. Sadeghi, A BP-neural network predictor model for plastic injection molding process, J. Mater. Process Tech., 103 (2000) 3, 411-416, doi:10.1016/S0924-0136(00)00498-2

${ }^{5}$ C. F. Juang, S. T. Huang, F. B. Duh, Mold temperature control of a rubber injection-molding machine by TSK-type recurrent neural fuzzy network, Neurocomputing, 70 (2006) 1-3, 559-567, doi:10.1016/j.neucom.2005.11.003

${ }^{6}$ C. Karatas, A. Sözen, E. Arcaklioglu, S. Ergüney, Modelling of yield length in the mould of commercial plastics using artificial neural networks, Mater. Design, 28 (2007) 1, 278-286, doi:10.1016/j.matdes. 2005.06.016 


\section{MATERIALI IN TEHNOLOGIJE/MATERIALS AND TECHNOLOGY (1967-2017) - 50 LET/50 YEARS}

\section{KRAMAR, D. CICA: PREDICTIVE MODEL AND OPTIMIZATION OF PROCESSING PARAMETERS ...}

${ }^{7}$ M. Altan, Reducing shrinkage in injection molding via the Taguchi, ANOVA and neural network methods, Mater. Design, 31 (2010) 1 , 599-604, doi:10.1016/j.matdes.2009.06.049

${ }^{8}$ H. Shi, Y. Gao, X. Wang, Optimization of injection molding process parameters using integrated artificial neural network model and expected improvement function method, Int. J. Adv. Manuf. Tech, 48 (2010) 9, 955-962, doi:10.1007/s00170-009-2346-7

${ }^{9}$ A. Krimpenis, P. G. Benardos, G. C. Vosniakos, A. Koukouvitaki, Simulation-based selection of optimum pressure die-casting process parameters using neural nets and genetic algorithms, Int. J. Adv. Manuf. Tech., 27 (2006) 5, 509-517, doi:10.1007/s00170-0042218-0

${ }^{10}$ C. Shen, L. Wang, Q. Li, Optimization of injection molding process parameters using combination of artificial neural network and genetic algorithm method, J. Mater. Process Tech., 183 (2007) 2-3, 412-418, doi:10.1016/j.jmatprotec.2006.10.036

${ }^{11}$ B. Ozcelik, T. Erzurumlu, Comparison of the warpage optimization in the plastic injection molding using ANOVA, neural network model and genetic algorithm, J. Mater. Process Tech., 171 (2006) 3, 437-445, doi:10.1016/j.jmatprotec.2005.04.120

${ }^{12}$ W. C. Chen, G. L. Fu, P. H. Tai, W. J. Deng, Process parameter optimization for MIMO plastic injection molding via soft computing, Expert Syst. Appl., 36 (2009) 2, 1114-1122, doi:10.1016/j.eswa. 2007.10.020

${ }^{13}$ E. Li, L. Jia, J. Yu, A genetic neural fuzzy system-based quality prediction model for injection process, Comput. Chem. Eng., 26 (2002) 9, 1253-1263, doi:10.1016/S0098-1354(02)00092-3

${ }^{14}$ D. Mathivanan, N. S. Parthasarathy, Sink-mark minimization in injection molding through response surface regression modeling and genetic algorithm, Int. J. Adv. Manuf. Tech., 45 (2009) 9-10, 867-874, doi:10.1007/s00170-009-2021-Z

${ }^{15}$ Y. M. Deng, Y. Zhang, Y. C. Lam, A hybrid of mode-pursuing sampling method and genetic algorithm for minimization of injection molding warpage, Mater. Design, 31 (2010) 4, 2118-2123, doi:10.1016/j.matdes.2009.10.026
${ }^{16}$ H. S. Park, T. T. Nguyen, Optimization of injection molding process for car fender in consideration of energy efficiency and product quality, J. Comput. Design. Eng., 1 (2014) 4, 256-265, doi:10.7315/ JCDE.2014.025

${ }^{17}$ J. Cheng, Z. Liu, J. Tan, Multiobjective optimization of injection molding parameters based on soft computing and variable complexity method, Int. J. Adv. Manuf. Tech., 66 (2012) 5, 907-916, doi:10.1007/s00170-012-4376-9

${ }^{18}$ J. Cheng, Y. Feng, J. Tan, W. Wei, Optimization of injection mold based on fuzzy moldability evaluation, J. Mater. Process Tech., 208 (2008) 1-3, 222-228, doi:10.1016/j.jmatprotec.2007.12.114

${ }^{19}$ K. T. Chiang, F. P. Chang, Application of grey-fuzzy logic on the optimal process design of an injection-molded part with a thin shell feature, Int. Commun. Heat Mass, 33 (2006) 1, 94-101, doi:10.1016/j.icheatmasstransfer.2005.08.006

${ }^{20} \mathrm{~K}$. T. Chiang, The optimal process conditions of an injection-molded thermoplastic part with a thin shell feature using grey-fuzzy logic: A case study on machining the PC/ABS cell phone shell, Mater. Design, 28 (2007) 6, 1851-1860, doi:10.1016/j.matdes.2006.04.008

${ }^{21}$ L. A. Zadeh, Fuzzy logic = computing with words, IEEE T. Fuzzy Syst., 4 (1996) 2, 103-111, doi:10.1109/91.493904

22 J. S. R. Jang, C. T. Sun, E. Mizutanim, Neuro-Fuzzy and Soft Computing: A Computational Approach to Learning and Machine Intelligence, Prentice Hall, New Jersey, 1997

${ }^{23}$ J. Kennedy, R. Eberhart, Particle swarm optimization, Proc. of 4th IEEE Int. Conf. on Neural Networks, Perth, 1995, 1942-1948

${ }^{24}$ D. C. Montgomery, Design and Analysis of Experiments, 5th ed., New York, Wiley, 2001 